\title{
Neonatal deafening causes changes in Fos protein induced by cochlear electrical stimulation
}

\author{
SHIGEYO NAGASE ${ }^{1}$, MASAHIRO MUKAIDA ${ }^{2}$, JOSEF M. MILLER ${ }^{1}$ \\ and RICHARD A. ALTSCHULER ${ }^{1, *}$ \\ ${ }^{1}$ Kresge Hearing Research Institute, Department of Otolaryngology, University of Michigan, Ann Arbor, MI 48109, USA; \\ ${ }^{2}$ Defense Medical College, Department of Forensic Medicine, Tokyo, Japan \\ shuler@umich.edu
}

Received 17 July 2002; revised 13 June 2003; accepted 24 August 2003

\begin{abstract}
The influence of neonatal deafness on cochlear electrically evoked Fos expression in the auditory brainstem was examined. Newborn rats were deafened by systemic injection of kanamycin, $1 \mathrm{mg} / \mathrm{g}$ daily for 12 days. At 4, 5, 6 or 8 weeks of age, these animals received cochlear electrical stimulation with a basal monopolar electrode for 90 minutes. Age-matched untreated control animals received similar stimulation. Experimental and control animals were assessed for spiral ganglion cell densities and Fos immunoreactive staining in the central nucleus of the inferior colliculus. Spiral ganglion cell assessments showed significant decreases in spiral ganglion cell densities in deafened rats compared to age-matched controls, at 5 weeks of age in lower turns and 6 and 8 weeks in all turns. Cochlear electrical stimulation induced Fos immunoreactive staining in the nucleus of auditory brain stem neurons in treatment and control groups. A significantly greater number of Fos immunoreactive neurons was found in the contralateral central nucleus of inferior colliculus in 5, 6 and 8 week old deafened animals compared to age-matched controls. The increases were larger with a longer duration of deafness. These results suggest that there are changes in auditory processing as a consequence of neonatal deafness.
\end{abstract}

\section{Introduction}

There are an increasing number of children who receive cochlear prostheses at an early age. Prelingually deaf children with cochlear implants demonstrate much slower learning curves than postlingually deaf children (Fryauf-Bertschy et al., 1992). Preoperative factors including age at time of implantation, length of deafness, and etiology of deafness, linguistic competence and mode of communication appear to affect outcomes (Gantz et al., 1994; Tyler \& Summerfield, 1996). Some reports have implied that children implanted at an early age receive more benefit than children with a longer duration of deafness. It is still unclear whether the effect of length of deafness relates to a decrease in the number of surviving spiral ganglion cells in the cochlea, to the distribution of functional neurons in the cochlea, to plasticity of higher auditory centers, or to a combination of all those mechanisms. Learning abilities are also dependent on the functional changes in the central nervous system. Because of degraded auditory input and auditory feedback, deaf children may rely on alternative forms of input and feedback as they attempt to develop intelligible speech.
It is therefore important to develop animal models of early acquired profound hearing loss to evaluate how auditory neurons and auditory processing change as a consequence of neonatal deafness. The inferior colliculus is a major auditory brain stem processing center. It receives predominantly contralateral excitatory monaural inputs from the cochlear nucleus as well as bilateral excitatory and inhibitory binaural information from the nuclei of the superior olivary complex and nuclei of the lateral lemniscus. There is growing evidence that deafness induces changes in inhibitory neurotransmission in the central nucleus of the inferior colliculus (CIC) resulting in less inhibition (Bledsoe et al., 1995; Mossop et al., 2000; Potashner et al., 2000) and we have shown that this is accompanied by changes in Fos immunostaining (Nagase et al., 2000). We found that following 21-days of deafness in mature rats, cochlear electrical stimulation induced more Fos immunoreactive (IR) neurons in the CIC than in agematched normal hearing rats. Fos acts as a transcription factor to regulate expression of target genes (Sheng \& Greenberg, 1990; Morgan \& Curran, 1991) and can

* To whom correspondence should be addressed. 
serve as a marker of neural activity. The advantage of using Fos protein is based on its cell specific expression as opposed to electrophysiological field studies or 2deoxyglucose studies which address activity in a larger region. It is important, however to be aware of the limitations of the method. Fos expression is sensitive to the state of arousal of a preparation (e.g. Sharp et al., 1991; Asmus \& Newman, 1994) and non-stimulated controls are therefore important. Studies in the auditory system also show that the thresholds for induction can vary for different cell types in different regions. Therefore while it can be valuable to compare induction in the lower threshold neurons between conditions, it must be kept in mind that other neurons may also be active but are not immunostained. In the CIC we have found that Fos immunostaining is induced in most principal cells at 3-5× threshold (Saito et al., 1999, 2000; Nagase et al., 2000), making this a good region for analysis. The purpose of the present study was to determine how Fos immunostaining in the $\mathrm{CIC}$ changes as a consequence of neonatal deafness.

\section{Materials and methods}

\section{GENERAL}

Sprague-Dawley rats (250-350 g) were used in these experiments. Newborn rats were deafened by $1 \mathrm{mg} / \mathrm{g}$ of intramuscular kanamycin injection every day for 12 days after birth. At 4 (37-46 g), 5 (72-79 g), 6 (106-161 g) or 8 (181-252 g) weeks of age, a monopolar electrode was placed in the basal turn of the cochlea. Age-matched normal hearing animals were also implanted. Neonatally deafened rats and age-matched controls received 90 minutes of cochlear electrical stimulation. Thirty minutes following cessation of stimulation, animals were fixed and assessed for Fos immunostaining in sections through the inferior colliculus. Age-matched rats without electrical stimulation were assessed as non-stimulated controls. All experimental groups contained five rats, except non-stimulated controls ( 2 for each group).

\section{SURGICAL PREPARATION}

A single Teflon coated 3T Pt-Ir wire with a $250 \mu \mathrm{m}$ diameter ball-tip at the base was used to stimulate the inner ear. A $5 \mathrm{~T}$ Pt-Ir wire without Teflon insulation was used as an indifferent electrode, placed along the bone of the bulla.

At $4,5,6$ or 8 weeks of age, animals were anesthetized with ketamine $(75 \mathrm{mg} / \mathrm{kg})$ and xylazine $(8 \mathrm{mg} / \mathrm{kg})$ and aseptic procedures were followed. For deafened groups, the auditory brain stem response (ABR) was used to determine thresholds. The cochlea was exposed via a post-auricular approach. A small hole was made in basal turn of the cochlea, anterior to the round window membrane. The monopolar electrode was placed approximately $2 \mathrm{~mm}$ into the scala tympani of the basal turn and secured at the cochlear defect with carboxylate cement. The indifferent wire was placed in the middle ear. The electrodes terminated at a transcutaneous connector that was mounted with screws and methacrylate to the skull. In addition, a stainless steel vertex epidural electrode was threaded into the skull midway between bregma and lambda for electrophysiological studies.

\section{PHYSIOLOGICAL RECORDING PROCEDURES}

Electrical evoked ABR (EABRs) from $50 \mu$ sec pulses were recorded with a preamplifer (Sanei 7S12) after implantation. The amplifier band pass was set at 0.1 to $10 \mathrm{KHz}$. Rectangular current pulses, alternating in polarity presented at $50 \mu \mathrm{sec}$ intervals, were generated by a constant current source. 1000 sweeps were averaged to define a given response. Threshold was defined as the minimum peak intensity of stimulation that evoked a visually detectable consistent waveform. Electrical stimulation at a peak current level of $5 \times$ (times) EABR thresholds was given to the deafened and age-matched control groups. Stimulation was provided within a sound deafened, double wall booth, with an isolated constant current stimulator for 90 minutes in all groups. Stimuli were $50 \mu \mathrm{sec} /$ phase biphasic, charge balanced square waves delivered at 100 pulses/sec.

\section{HISTOLOGICAL PROCEDURES}

Thirty minutes after the cessation of stimulation, animals were heavily anesthetized with chloral hydrate and perfused through the ascending aorta with $300 \mathrm{ml}$ of $0.1 \mathrm{M}$ phosphate buffer (PB, pH 7.3) followed by 300-500 $\mathrm{ml}$ of paraformaldehyde $(4 \%)$ in $0.1 \mathrm{M} \mathrm{PB}$. The cochleae then received intrascalar local perfusion with the same fixative, followed by overnight immersion in this fixative. After decalcification with $10 \%$ EDTA solution for about 1 week, the cochleae were embedded in paraffin. Six micron sections were cut in a paramodiolar plane and every fifth section was stained with toluidine blue. The canal was divided into four segments, base (B), lower middle (LM), upper middle (UM), and apex (A). The number and density of spiral ganglion cells (SGCs) contained within each of these four profiles of Rosenthal's canal was determined using a computer-based morphometry station consisting of a Axiovert 135 microscope with a video camera (Panasonic, KS102). Five mid-modiolar sections from each ear were randomly selected and used in the statistical analysis of spiral ganglion cell density. For each section, for each of the four profiles of Rosenthal's canal, the number of SGCs (identified by size and shape criteria) was entered and then the outline of Rosenthal's canal traced to give its area. The number of SGC in each profile was then divided by the area of that profile to give a measure of SGC density. These were then averaged for each group. The spiral ganglion cell density for each profile was then compared between groups by the Student $T$-test.

Perfused brains were postfixed in the same fixative for 2 hours at $4^{\circ} \mathrm{C}$ and then placed in $20 \%$ sucrose in PB overnight at $4{ }^{\circ} \mathrm{C}$. The auditory brain stem was then frozen on a cryostat chuck and $50 \mu \mathrm{m}$ frontal sections were cut on a Hacker Bright cryostat. Free-floating sections were pre-incubated with $2 \%$ normal goat serum in phosphate buffered saline (PBS) containing $1 \%$ bovine serum albumin, $0.3 \%$ Triton $\mathrm{X}-100$ (PBS-T) for 60 minutes at room temperature. Sections were then incubated with primary antibody to Fos protein (Oncogene Sciences) diluted 1:2000 in PBS-T with 2\% normal goat serum for 48 hours at $4^{\circ} \mathrm{C}$. Sections were rinsed 3 times with PBS (15 minutes per wash) and incubated with biotinylated goat anti-rabbit antiserum (Vector Laboratories) for 90 minutes. 
After three washed in PBS, sections were incubated with an avidin-biotin peroxidase complex (ABC) solution (Vector) for 1 hour, rinsed 3 times in PBS and placed in diaminobenzidine tetrahydrochloride with the addition of nickel chloride (Vector Laboratories) for 2-3 minutes. The peroxidase reaction was then visualized with the addition of $\mathrm{H}_{2} \mathrm{O}_{2}$. Tissue sections were mounted onto chrome-alum, gelatin-subbed slides. Each section was examined by light microscopy. Sections were photographed and the immunoreactive cells were mapped using a camera lucida. While changes and/or differences were apparent in qualitative assessments, quantitative measures were also done to determine the extent of the changes in the central CIC. From comparable sections (based on morphological landmarks) containing the contralateral central portion of the CIC, 5 sections were randomly selected for each of the five animals in each group for quantitative as- sessment. All neurons with moderate-heavily stained nuclei ( $5 \times$ difference in pixel intensity) in the CIC in each section were counted. Comparison between groups was made using the Student $T$-test.

\section{Results}

\section{SPIRAL GANGLION CELLS}

In 4-week old deafened animals, there was outer hair loss in lower turns. No difference was found in the SGC density between deafened and control ears (Fig. 1). In 5-week old deafened animals, however, significant decreases in SGC densities were seen in basal turn profiles of Rosenthal's canal (Fig. 2E and F) compared to normal hearing controls (Fig. 2A and B). These deafened
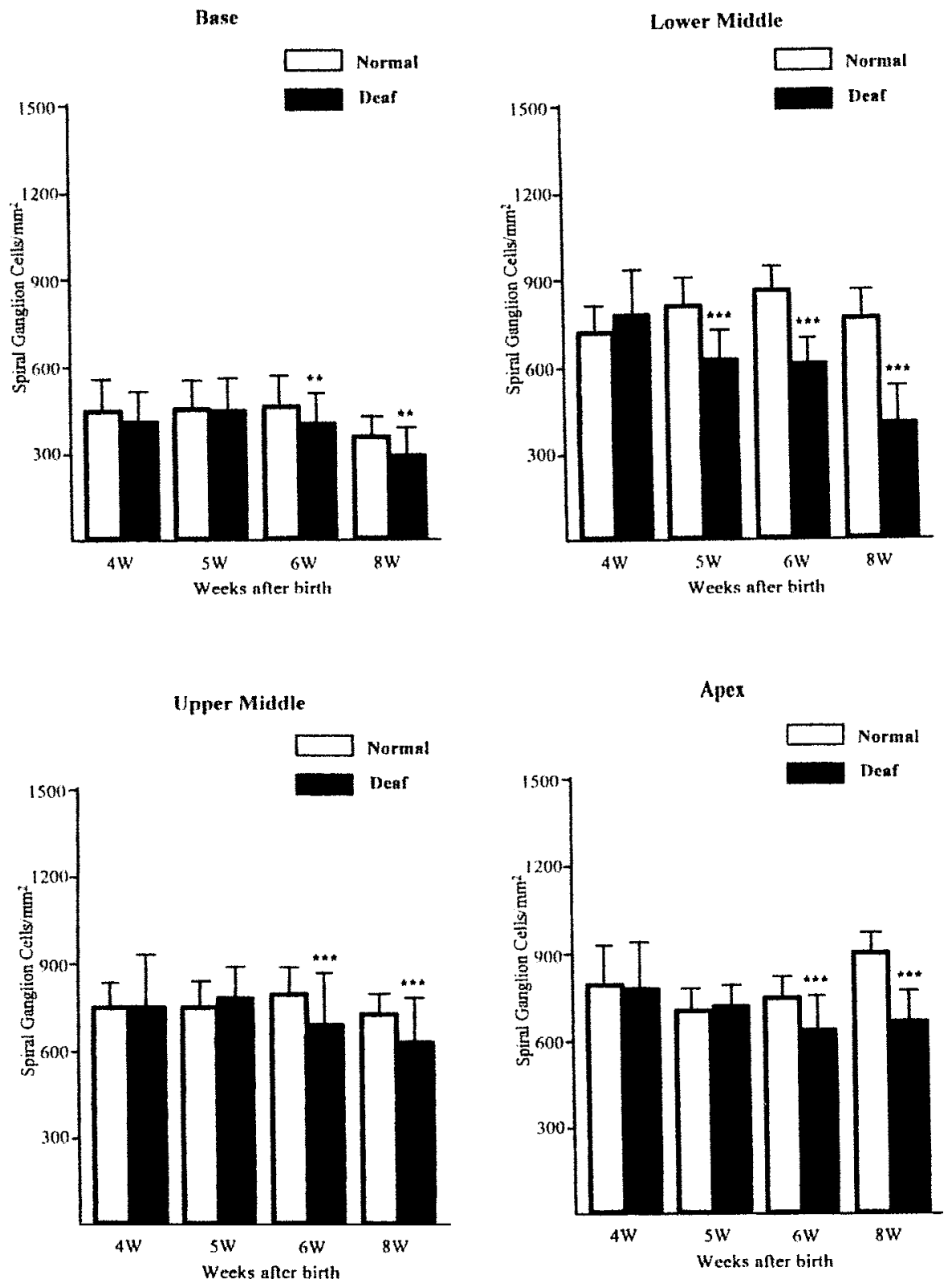

Fig. 1. Mean and standard deviation of the number of spiral ganglion cells $/ \mathrm{mm}^{2}$ in profiles from the base, lower middle, upper middle and apical turns of the cochlear spiral for each group. Bars show standard deviation. 

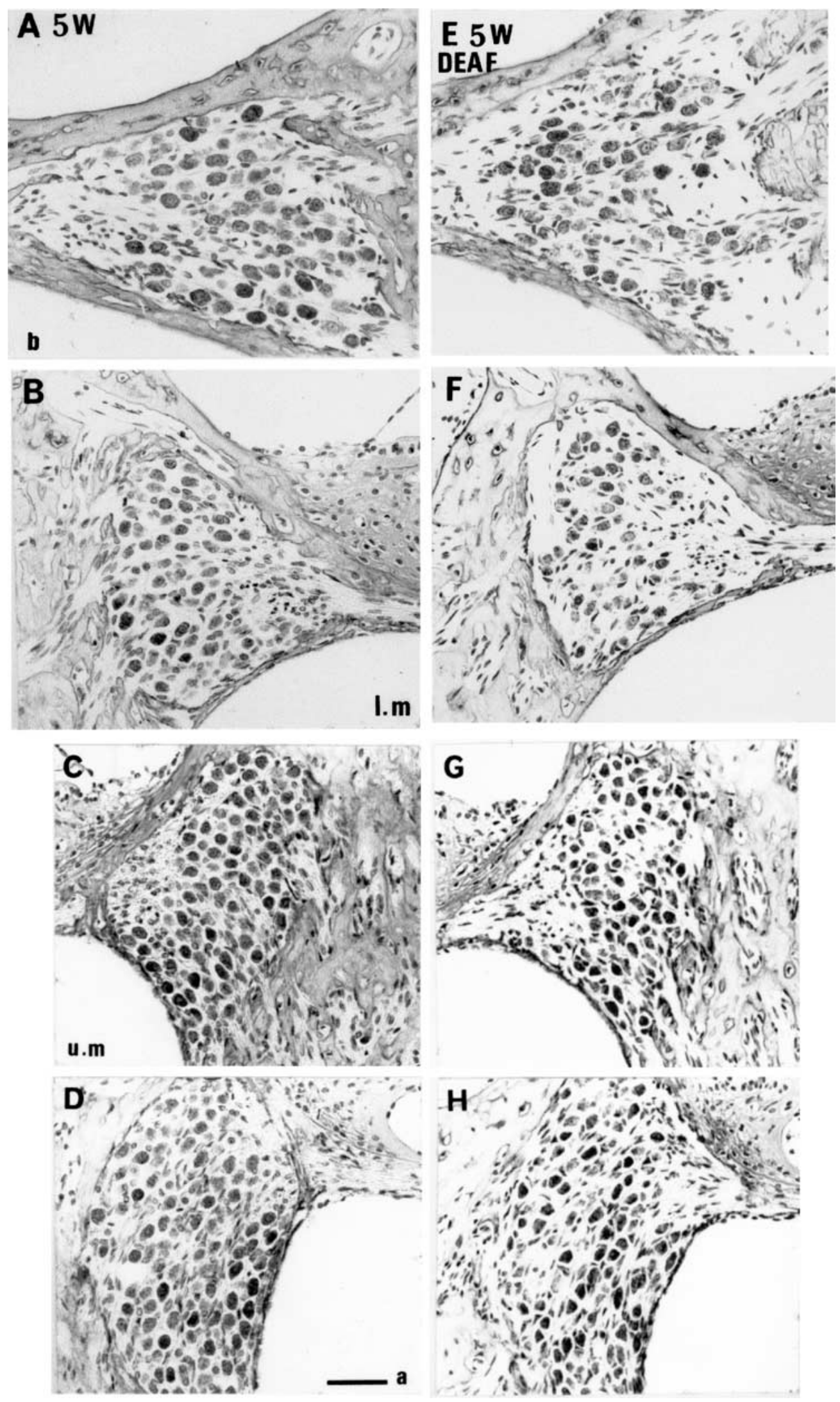

Fig. 2. Photomicrographs of the spiral ganglion cells in the base (A), lower middle (B), upper middle (C), and apical (D) turn of Rosenthal's canal in 5-week control rats versus spiral ganglion cells in the base (E), lower middle (F), upper middle (G) and apex $(\mathrm{H})$ in 5-week neonatally deaf rats. Scale bar $=50 \mu$. 

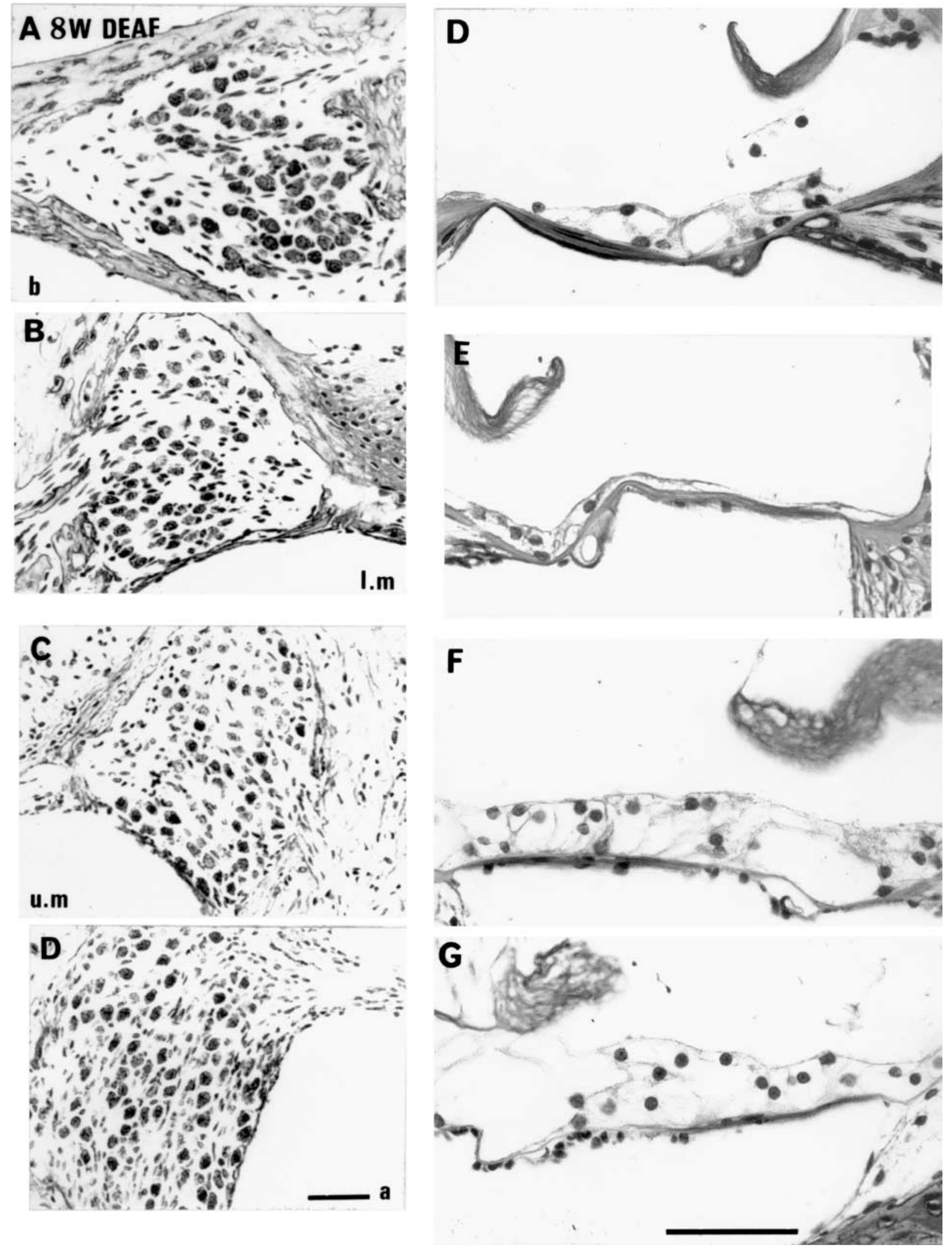

Fig. 3. Photomicrographs of the spiral ganglion cells in the base (A), lower middle (B), upper middle (C) and apex (D) turn of Rosenthal's canal and of the organ of Corti in the base (E), lower middle (F), upper middle $(\mathrm{G})$ and apex $(\mathrm{H})$ turn of Rosenthal's canal in 8-week neonatally deaf rats. Scale bar $=50 \mu$. 
ears showed almost complete loss of hair cells in lower turns. In 6- and 8-week old deafened animals, a statistically significant decrease in SGC densities was found in the all turns (Fig. 1). All of the deafened ears showed complete loss of hair cells in basal and lower middle turns (Fig. 3).

\section{FOS IMMUNOLABELING IN THE CIC}

Specific Fos IR staining was confined to the nucleus of neurons. Fos IR was not observed in the absence of electrical stimulation. Differences between deafened and age-matched control animals in cochlear electrical stimulation induced Fos immunostaining were observed.

In 4-week old deafened animals, only a small number of Fos IR principal cells in the high frequency region of the contralateral CIC were evoked by cochlear electrical stimulation, with no significant difference in age-matched controls (Fig. 4). In 5-, 6- and 8-week old deafened animals, however, a significant difference was found between deafened animals and age-matched controls. The number of Fos IR principal cells was significantly greater in the deafened animals compared to age-matched normal hearing controls (Figs. 4-6). In addition, the number of Fos IR neurons induced by cochlear electrical stimulation increased at each time point following deafness (Figs. 4-6). By 8 weeks, in deafened animals there was a prominent broad band of Fos IR labeled neurons that filled two-thirds of the contralateral CIC (Figs. 5F, 6B and D). Age-matched control groups show significantly fewer Fos IR neurons that were confined to the high frequency region of the contralateral CIC (Fig. 5A-C).

\section{Discussion}

The results of the present study indicate that a significant loss of SGCs in all turns is found at 8 weeks following deafening and the greatest SGC losses are seen in the lower middle turn of the cochlea. Leake-Jones

\section{contralateral CIC}

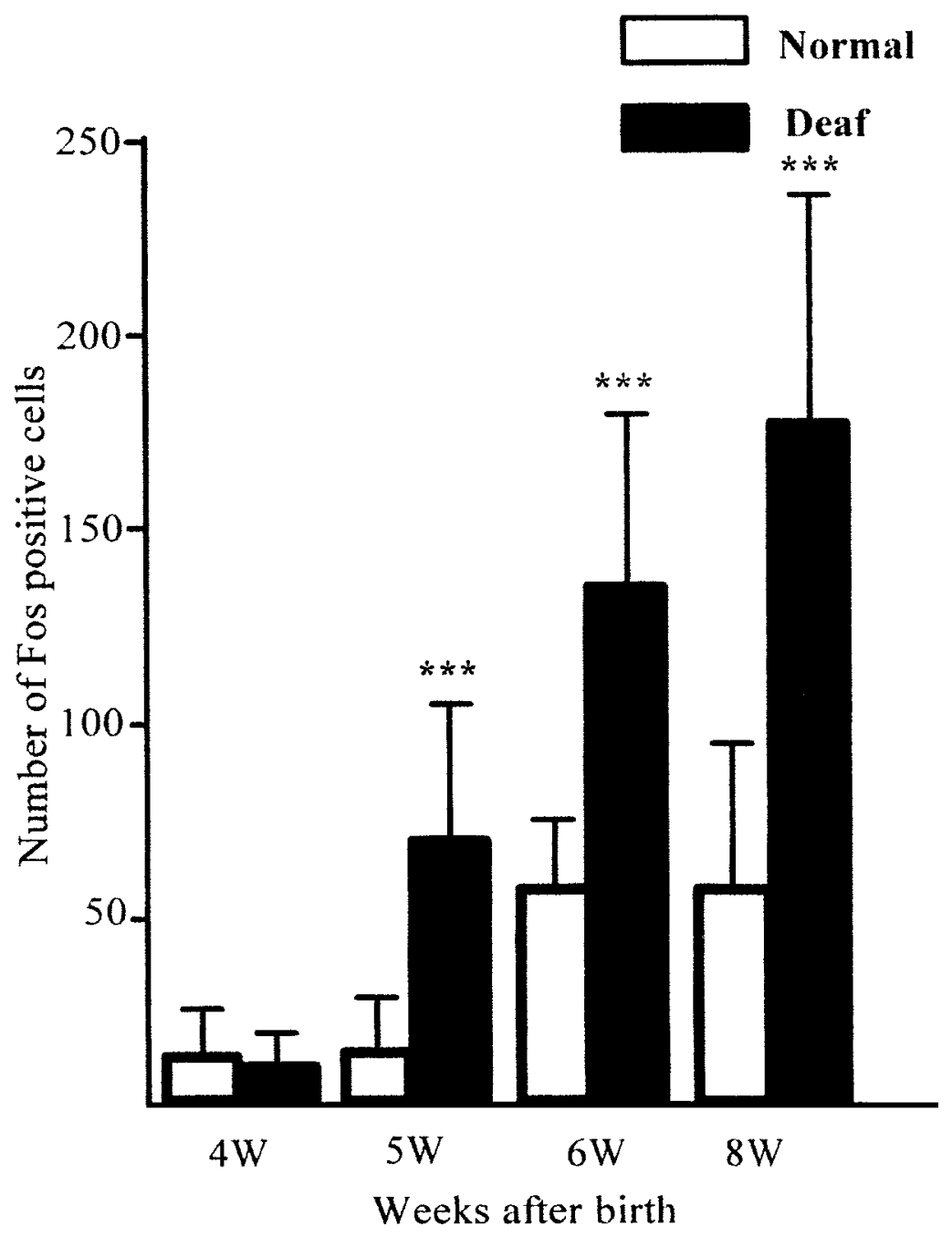

Fig. 4. Bar graph with counts of Fos-positive neurons from the contralateral CIC at 4-, 5-, 6- and 8-week deafness comparing age matched control animals. Bars show standard deviation. 

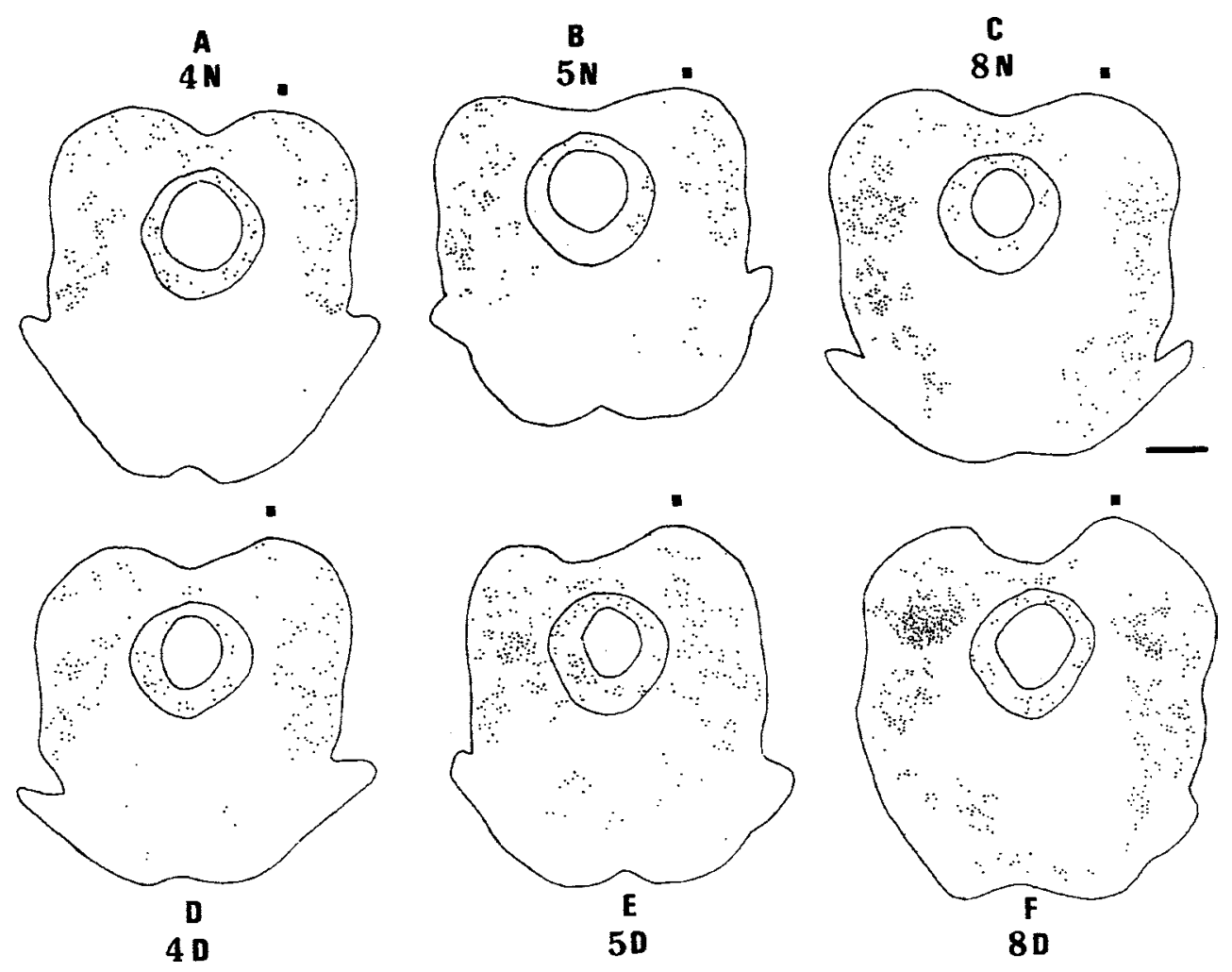

Fig. 5. Low power camera lucida drawings of representative sections through the rat inferior colliculus and lateral lemniscus, showing typical patterns of Fos IR neurons induced by cochlear electrical stimulation. A: 4-week control rat. B: 5-week control rat. C: 8-week control rat. D: 4-week neonatally deaf rat. E: 5-week neonatally deaf rat. F: 8-week neonatally deaf rat. Bar $=$ $1 \mathrm{~mm}$. Filled square ( $\mathbf{\square})$ shows the side ipsilateral to the stimulated cochlea.

et al. (1982) reported that the systemic administration of ototoxic drug induced rapid, severe and selective destruction of hair cells. Leake and Hradek (1988) also found that the time course of spiral ganglion cell loss in neonatal cats appear to be accelerated, since degeneration observed in these cats at about 30 weeks of age was more severe than that observed in adult cats one year after drug treatments. In the present study the degeneration of sensory cells was already seen at 4 weeks of age in lower turns although the neural degeneration varied among individual animals. It was rare to see inner hair cell or supporting cell loss without significant SGC loss in the corresponding area of Rosenthal's canal.

Fos-immunostaining results are consistent with other studies examining activation of central auditory structures following acoustic stimulation (Ehret \& Fischer, 1991; Friauf, 1991; Lim et al., 1991; Sato et al., 1992, 1993; Rouiller et al., 1992; Adams, 1995; Brown \& Liu, 1995) as well as electrical stimulation (Vischer et al., 1994; Zhang et al., 1996; Saito et al., 1999, 2000; Nagase et al., 2000). Results of the present experiments demonstrate that cochlear electrical induction of Fos immunoreactivity was less in 4-week old animals, either normal hearing or deafened. Deafened animals showed increased cochlear electrical stimulation induced Fos expression in the CIC at 5, 6 and 8 weeks.
Increases in the number of induced Fos IR neurons in the CIC were larger with the longer duration of deafness. The increasing loss of SGC, in deafened animals may lead to broader excitation of the remaining auditory nerve and a wider band of excitation in the CIC. The increased number of Fos IR neurons could also result from central auditory changes with deafness. Bledsoe et al. (1995) also found that, in normal hearing animals, electrical stimulation resulted in suppression of activity in $40 \%$ of units examined. However, with deafness this suppression was transiently lost, 10-30 days following deafness. The loss of suppression correlated with decreases in GABA release (Bledsoe et al., 1995). Gerken (1979) showed a reduction of electrical stimulation thresholds throughout the cochlear nucleus, the superior olivary complex, the nucleus of the inferior colliculus and the medial geniculate body after cochlear destruction in cats. Thus, central auditory processing is altered following peripheral damage. Nagase et al. (2000) also demonstrated that profound deafness resulted in an increased number of Fos IR neurons over that seen in normal hearing animals in the contralateral CIC. There may therefore be a loss of inhibition in central pathways with deafness in either the adult or neonate, leading to an increase in the number of Fos IR labeled, excited neurons in the CIC. 


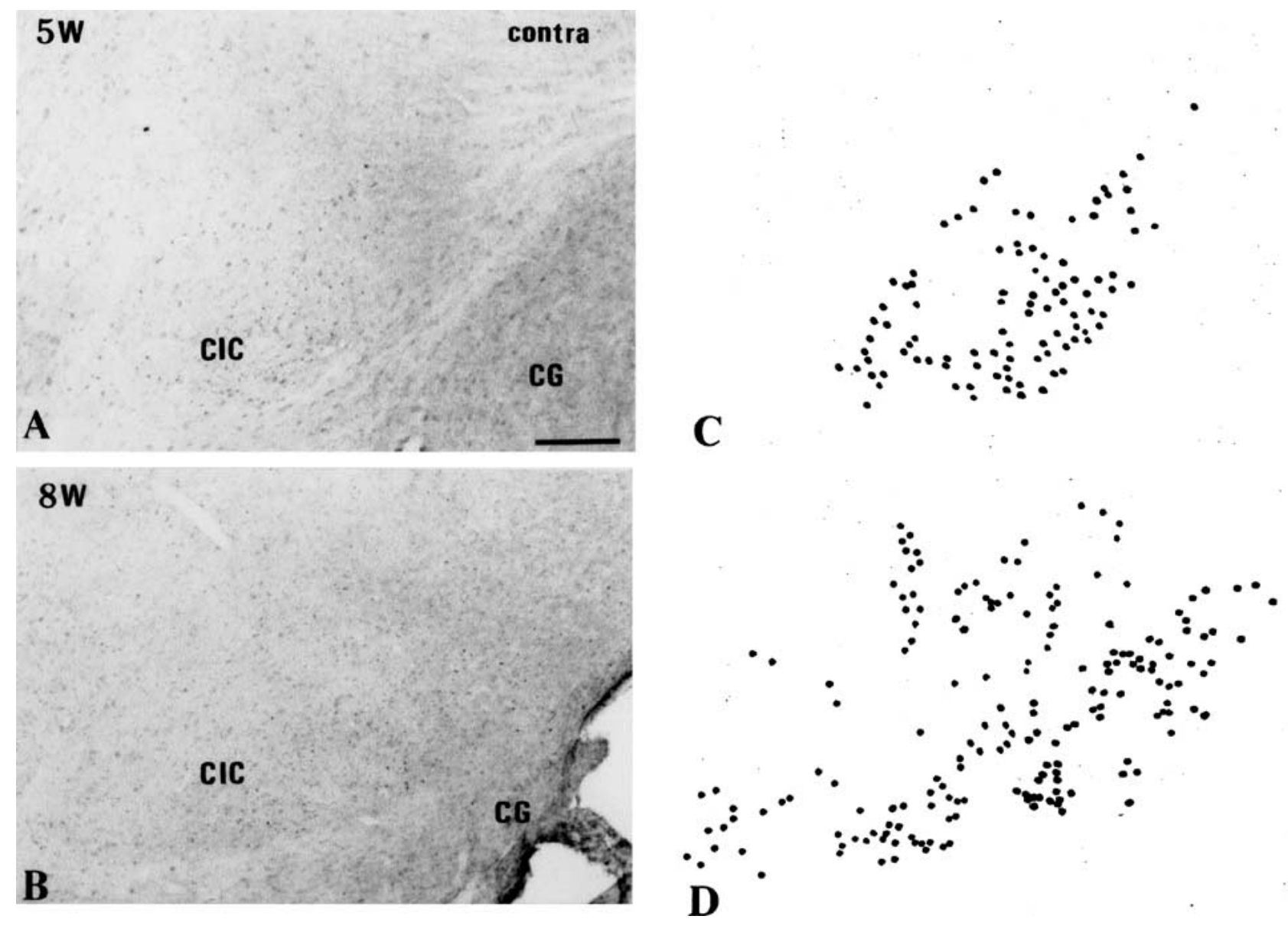

Fig. 6. Photomicrographs and camera lucida drawings of the contralateral central nucleus of inferior colliculus. A and C: 5-week neonatally deaf rat. B and D: 8-week nenatally deaf rat. More Fos IR neurons are induced in 8-week deaf rat (B and D) than in 5-week deaf rat (A and C). Bar $=100 \mu$.

Heid et al. (1997) reported that main afferent projection from the cochlear nucleus to the inferior colliculus in congenital deaf cats was unchanged and this projection is tonotopically organized in spite of congenital auditory deprivation. However, other auditory brain stem features may also be influenced by the "quiet environment" during development, in addition to the changes observed following deafness in the mature animal.

Changes in the central auditory system as a consequence of deafness may have an impact on auditory processing. Fryauf-Bertschy et al. (1994) reported that postlingually deafened children achieve significant better speech perception abilities when compared to children with prelingually acquired deafness of congenitally deaf children after 1 year of implant experience. Many reports show a devastating effect on the intelligibility and language development of most children profoundly deaf before the age of 3 years. Waltzman et al. (1994) suggest that the deaf child, if given greater access to auditory input earlier, by receiving cochlear implant at a younger age, could achieve a higher level of performance and obtain increased benefit. Due to a very high proportion of the variance within groups of implant users, the appropriate time of implantation for prelingually deafened children is unknown, although there might be an upper age limit. However there is no question that the age of implantation is also an important factor that affects the improvement in prelingually deafened children. It will be interesting in future studies to test the reversibility of deafness-related changes in central auditory pathways, which might have important implications for timing of cochlear implantation in children.

\section{References}

ADAMS, J. C. (1995) Sound stimulation induces Fos-related antigens in cells with common morphological properties throughout the auditory brainstem. Journal of Comparative Neurology 361, 645-668.

ASMUS, S. E. \& NEWMAN, S. W. (1994) Colocalization of tyrosine hydroxylase and Fos in the male Syrian hamster brain following different states of arusal. Journal of Neurobiology 25, 156-168.

Bledsoe, S. C., Nagase, S., Miller, J. M., \& Altschuler, R. A. (1995) Deafness-induced plasticity in the mature central auditory system. NeuroReport 7, 225-229. 
BROWN, M. C. \& LIU, T. S. (1995) Fos-like immunoreactivity in central auditory neurons of the mouse. Journal of Comparative Neurology 357, 85-97.

EHRET, G. \& FISCHER, R. (1991) Neuronal activity and tonotopy in the auditory system visualized by $c$-fos gene expression. Brain Research 567, 350-354.

FRIAUF, E. (1991) c-fos immunohistochemistry reveals no shift of tonotopic order in the central auditory system of developing rats. Society for Neuroscience Abstracts 17, 123.

FRYAUF-BERTSCHY, H., TYLER, R., KELSAY, D. \& GANTZ, J. B. (1992) Performance over time of congenitally deaf and postlingually deafened children using a multichannel cochlear implant. Journal of Speech and Hearing Research 35, 913-920.

GANTZ, J. B., TYLER, T. R., WOODWORTH G. G., TYEMURRAY, N. \& FRYAUF-BERTSCHY, H. (1994) Results of multichannel cochlear implants in congenital and acquired prelingual deafness in children: Five-year follow-up. American Journal of Otology 15, 9-13

GERKEN, G. M. (1979) Central denervation hypersensitivity in the auditory system of the cat. Journal of Acoustical Society of America 66, 721-727

HEID, S., JÄHN-SIEBERT, T. K., KLINKE, R., HARTMANN, R. \& LANGNER, G. (1997) Afferent projection patterns in the auditory brainstem in normal and congenitally deaf white cats. Hearing Research 110, 191-199.

LEAKE-JONES, P. A., VIVION, M. C., O'REILLY, B. F. \& MERZENICH, M. M. (1982) Deaf animal models for studies of a multichannel cochlear prosthesis. Hearing Research 8, 225-246.

LEAKE, P. A. \& HRADEK, G. T. (1988) Cochlear pathlogy of long term neomycin induced deafness in cats. Hearing Research 33, 11-34.

LIM, A., MYERS, M. W., MILLER, J. M. \& ALTSCHULER, R. A. (1991) C-fos expression in rat auditory nuclei following high-intensity acoustic stimulation. Society for Neuroscience Abstract 17, 163.

MOSSOP J. E., WILSON M. J., CASPARY D. M. \& MOORE D. R. (2000) Down-regulation of inhibition following following unilateral deafening. Hearing Research 147, 183-187.

MORGAN, J. I. \& CURRAN, T. (1991) Stimulustranscription coupling in the nervous system: Involvement of the inducible proto-oncogenes fos and jun. Annual Review of Neuroscience 14, 421-451.

NAGASE, S., MILLER, J. M., DUPONT, J., LIM, H. H., SATO, K. \& ALTSCHULER R. A. (2000) Changes in cochlear electrical stimulation induced Fos expression in the rat inferior colliculus following deafness. Hearing Research 147, 242-250.

POTASHNER, S. J., SUNEJA, S. K., BENSON, C. G. (2000) Altered glycinergic synaptic activities in guinea pig brain stem auditory nuclei after cochlear ablation. Hearing Research 147, 125-136.

ROUILLER, E. M., WAN, X. S. T., MORET, V. \& LIANG, F. (1992) Mapping of $c$-fos expression elicited by pure tones stimulation in the auditory pathways of the rat, with emphasis on the cochlear nucleus. Neuroscience Letters 144, 19-24.

SAITO, H., MILlER, J. M., PFINGST, B. E. \& ALTSCHULER, R. A. (1999) Fos immunoreactivity in the auditory brain stem evoked by bipolar intracochlear electrical stimulation: Effects of current level and pulse duration. Neuroscience 91, 139-161.

SAITO, H., MILLER, J. M. \& ALTSCHULER, R. A. (2000) Cochleotopic Fos immunoreactivity in the cochlea and cochlear nuclei evoked by bipolar cochlear electrical stimulation. Hearing Research 145, 37-51.

SATO, K., HOUTANI, T., UEYAMA, T., IKEDA, M., YAMASHITA, T., KUMAZAWA, T. \& SUGIMOTO, T. (1992) Mapping of the cochlear nucleus subregions in the rat with neuronal Fos protein induced by acoustic stimulation with low tones. Neuroscience Letters 142, $48-52$.

SATO, K., HOUTANI, T., UEYAMA, T., IKEDA, M., YAMASHITA, T., KUMAZAWA, T. \& SUGIMOTO, T. (1993) Identification of rat brainstem sites with neuronal fos protein induced by acoustic stimulation with pure tones. Acta Otolaryngologica 500, 18-22.

SHARP, F. R., SAGAR, S. M., HICKS, K., LOWENSTEIN, D. \& HISANAGA, K. (1991) c-fos mRNA, Fos and Fosrelated antigen induction by hypertonic saline and stress. Journal of Neuroscience 11, 2321-2331.

SHENG, M. \& GREENBERG, M. E. (1990) The regulation and function of $c$-fos and other immediate early genes in the nervous system. Neuron 4, 477-485.

TYLER, R. S. \& SUMMERFIELD, A. Q. (1996) Cochlear implantation: Relationships with research on auditory deprivation and acclimatization. Ear and Hearing 17, 38-50.

VISCHER, M. W., HAUSLER, R. \& ROUILLER, E. M. (1994) Distribution of Fos-like immunoreactivity in the auditory pathway of the Sprague-Dawley rat elicited by cochlear electrical stimulation. Neuroscience Research 19, 175-185.

WALTZMAN, S. B., COHEN, N. L., GOMOLIN, R. H., SHAPIRO, W. H., OZDAMAR, S. R. \& HOFFMAN, R. A. (1994) Long-term results of early cochlear implantation in congenitally and prelingually deafened children. American Journal of Otology 15, 9-13.

ZHANG, J. S., HAENGGELI, C. A., TEMPINI, A., VISCHER, M. W., MORET, V. \& ROUILLER, E. M. (1996) Electrically induced Fos-like immunoreactivity in the auditory pathway of the rat: Effects of survival time, duration, and intensity of stimulation. Brain Research Bulletin 39, 75-82. 